\title{
La economía mexicana, un lento proceso de reestructuración
}

The Mexican economy, a slow process of restructuring

\section{Jesús Lechuga Montenegro* y Abdiel Gutiérrez Mendoza**}

\section{Resumen}

Con una apertura agresiva y numerosos acuerdos comerciales firmados, esto no ha tenido el efecto deseado o los resultados han sido muy pobres en términos de crecimiento. La investigación proporciona evidencia de que las políticas de liberalización del comercio y el TLCAN, así como un proceso devaluatorio y flexibilidad del tipo de cambio contribuyeron a la creación de un modelo dual, de alto dinamismo en las exportaciones manufactureras con una balanza comercial superavitaria con EU y un pobre desempeño del PIB. De otra parte, la baja de la tasa de interés real no ha estimulado la Formación Bruta de Capital Fijo, y no se modifica el modelo exportador manufacturero de bajo valor agregado, acentuando la dependencia de importaciones de bienes intermedios. Se muestra que el efecto de la política de equilibrio fiscal puede estar asociado con bajas tasas de acumulación.

Palabras clave:

- Apertura comercial

- Crecimiento liderado por exportaciones

- Formación de capital

\section{Abstract}

With an agressive openess and numerous trade agreements signed, this has not had the desired effect or the results have been very poor in terms of growth. The research provides evidence that the policies of trade liberalization and NAFTA, as well as a devaluation process and the flexibility of the exchange rate contribute to the creation of a dual model, highly dynamic manufacturing exports with a surplus trade balance with U.S and a poor GDP performance. Moreover, the decline in the real interest rate has not stimulated the Gross Fixed Capital Formation, and the manufacturing exporting low value-added model is unchanged, emphasizing the dependence on imports of intermediate goods. It is shown that the effect of the policy of fiscal balance may be associated with low rates of accumulation.

Keywords:

- Trade Liberalization

- Export-Led Growth

- Investment

JEL: O11, F11, O24

\section{Introducción}

El agotamiento del modelo de industrialización por sustitución de importaciones, un alto déficit fiscal, inflación y la desaceleración aunados a la caída internacional de los precios del petróleo, fueron los síntomas de la desestructuración de las pautas de crecimiento observado hasta entonces en la economía mexicana; de donde surge la necesidad de perfilar un nuevo modelo. Como resultado, se orientaron políticas hacia la apertura comercial y liberalización financiera que pretendía la dinamización y saneamiento de la economía frente a una severa crisis de deuda, mismas que concluyeron con la firma del Tratado de Libre Comercio de América del Norte en 1994.

* Departamento de Economía. UAM-Azcapotzalco.montenegro@azc.uam.mx ** Licenciatura en Economía. UAM-Azcapotzalco. absgume@gmail.com 
El resultado de dichas políticas durante las últimas tres décadas ha sido deficiente con respecto a los resultados deseados, si bien la apertura de los mercados suponía mejoras productivas como atractivo a la inversión y con relaciones de comercio fluidas, impulsando de una manera dinámica la actividad exportadora y el desarrollo tecnológico. En cambio se ha observado un crecimiento aletargado de la producción que no va en correspondencia con el dinamismo del sector externo.

En América Latina el caso de la economía mexicana es único por cuanto el comercio exterior está altamente concentrado en EU y se tiene un modelo secundario exportador concentrado a su vez en sectores intensivos en tecnología y no en recursos naturales. E internamente hay inercias propias que bloquean la formación de capital en donde las políticas públicas implementadas, en particular la fiscal, no han sido un motor eficiente de la inversión. El objetivo del artículo es analizar esta doble vertiente en un contexto que puede caracterizarse como un modelo dual de auge exportador manufacturero y estabilidad con estancamiento.

El artículo está dividido en tres partes. La primera analiza el tipo de cambio y la inflación en México y Estados Unidos, observando los efectos que las políticas antes mencionadas tuvieron en el comportamiento de estas variables y en las relaciones comerciales; se hace una estimación del impacto del PIB de EU y el tipo de cambio en la balanza comercial del país. En la segunda parte se analiza la tasa de interés real y la Formación Bruta de Capital Fijo como parámetros para definir los niveles de inversión en bienes de capital resultante de las fluctuaciones de la tasa de interés. En la parte final se hace un análisis de las finanzas públicas y el déficit presupuestal respecto al endeudamiento y el efecto en la captación fiscal y sus repercusiones en los niveles de inversión pública.

\section{La paradoja del nuevo modelo dual}

El éxito exportador manufacturero no ha actuado como un motor de arrastre de la economía en su conjunto ni ha estimulado en forma consistente la innovación y el desarrollo tecnológico. Y la persistencia del bajo crecimiento deja en claro que una estrategia que ha priorizado los equilibrios macroeconómicos debe ser revisada sustancialmente. La crítica cubre un amplio espectro metodológico. 


\section{a) Semblanza}

La "Gran Transformación" que impulsaría el TLCAN no ha superado la dependencia del crecimiento económico de la capacidad para importar y las crisis de pagos externos en economía cerrada se han evitado o modulado a costa del crecimiento, situando al país en un paradójico "estancamiento estabilizador" (Cordera, 2015). En esta transformación se dan otras paradojas tales como el alto grado de apertura de México (64\%) muy superior al de EU (30\%), así como que el superávit comercial con este último no cubre el déficit con el resto de países; con lo cual "el perfil competitivo de las exportaciones mexicanas ocurre a nivel regional, pero se diluye en el marco de la globalidad" (Ruiz, 2015; 32).

La actividad exportadora conduce a la especialización y, de tratarse de manufacturas, esta especialización será dinámica en relación a aquella basada en recursos; se supone además que una economía apoyada en el paradigma del crecimiento liderado por las exportaciones en este caso manufactureras, será más dinámica que la que no lo hace.

De acuerdo con Capdevielle (2007), el nuevo modelo de inserción de México en la economía mundial en cadenas productivas de valor, se ha dado sin haber transitado con éxito hasta ahora hacia una construcción de capacidades que rompan con las inercias que obstaculizan el desarrollo. El sector manufacturero exportador es parte de un sistema productivo complejo y conforma el sector global de la economía con regímenes arancelarios ad hoc, que han favorecido un alto grado de especialización en pocas ramas; resultando en una nueva heterogeneidad estructural caracterizada por la coexistencia de dos procesos productivos: los articulados a redes globales y aquellos con relativa autonomía local. En este aspecto Ruiz (2015) señala que si bien la industria tuvo éxito en los sectores automotriz, electrónico y de productos químicos, no pudo transitar de la condición de centro ensamblador a integrante de las cadenas de valor.

De otra forma, la especialización en exportaciones manufactureras intensivas en tecnología ha resultado excluyente con el crecimiento liderado por la demanda interna (Fujii y Cervantes, 2013). Para estos autores la expansión de las exportaciones puede ampliar la demanda interna, en un escenario de crecimiento impulsado por los mercados externo e interno centrado en el valor agregado nacional indirecto (producción interna) más que en el directo (empleos, salarios, ganancias). 
El éxito exportador no ha estado asociado a una especialización dinámica en la cual se geste un núcleo endógeno de innovación y progreso técnico (Ros, 2008); dado que el alto componente de los insumos importados constriñe la actividad interna al ensamble con uso intensivo de mano de obra poco calificada y lleva a un bajo valor agregado en los bienes exportados.

En tanto que para Palley (2013) el paradigma del modelo de crecimiento comandado por las exportaciones ha agotado sus posibilidades debido a que la economía global enfrenta un déficit significativo de demanda, ejemplificado para EU en la saturación del endeudamiento de los consumidores; para México en el marco del TLC se tiene una situación paradójica en la cual los consumidores están en el norte y los productores en el sur, habida cuenta de que la adopción del modelo se dio en un contexto de globalización corporativa y de una estrategia no estrictamente nacional, sino que involucra a las economías en desarrollo, empresas multinacionales y economías desarrolladas. De tal forma que en la competencia sur-sur el principal competidor para México es China con grandes diferencias de productividad del trabajo, que en el periodo 1980-2008 tuvo un desempeño en cada país de -0.1 y 6.7\%, respectivamente (Palley, 2013).

En cuanto al pobre desempeño económico, este lo atribuye Loría (2009) a la inadecuada trayectoria de la composición sectorial (de la economía) y coloca el acento en la desviación hacia los servicios y la construcción -terciarización improductiva- con un efecto concomitante de desindustrialización; el resultado es una transición destructiva que ha debilitado los encadenamientos productivos, lo cual reduce la eficiencia de la inversión. Y Kehoe y Ruhl (2011) sitúan los magros resultados de las reformas aplicadas -fiscal, privatización, apertura y liberalización- en los problemas estructurales que derivan de un sistema financiero ineficiente, rigidez del mercado laboral y carencias del estado de derecho (falta de exigibilidad contractual o procesos de quiebra ineficientes), que llevan a una asignación errónea del trabajo y el capital; así como la falta de competitividad en sectores no manufactureros (petróleo, electricidad, telecomunicaciones, transporte) por la carencia de reformas específicas.

\section{b) "Los hechos estilizados"}

La alta concentración del comercio con eu da la impronta del sector externo de la economía mexicana, en la cual, a diferencia de Latinoamérica, las exportaciones están constituidas principalmente por manufacturas no intensivas en 
recursos (85\% del total) entre las cuales destacan tres ramas que concentran el 56\% del total (Máquinas y material eléctrico, Vehículos terrestres, Aparatos mecánicos y calderas; INEGI, 2012). Sin embargo, del lado de las importaciones el componente principal es el de bienes intermedios (74\%) siendo este modelo importador el soporte de las exportaciones, con lo cual el aporte del valor agregado interno en ellas es reducido, amén de que bloquea una integración robusta de la industria local. ${ }^{1}$

Con la apertura, en México se ha aplicado una política monetaria con tasas de interés variables y un tipo de cambio flexible. Dado que en el comercio exterior la fluctuación en el precio de las divisas tiene una influencia importante y debido a la alta concentración comercial con Estados Unidos, las variaciones monetarias influyen en la dinámica del producto nacional vinculado al ciclo de la economía de EU. ${ }^{2}$

La fluctuación controlada de la paridad dentro de una franja cambiaria en el periodo 1989-1994 permitió una estabilidad del peso en relación al dólar, así mismo el flujo de inversión extranjera fue importante pues se tenía confianza en los mercados mexicanos; no obstante un conjunto de conflictos sociales cuestionó la estabilidad a finales de 1994 provocando una fuerte salida de capitales reduciendo drásticamente las reservas nacionales y se abandonó la política monetaria efectuada hasta entonces, adoptando un tipo de cambio variable. ${ }^{3}$ Dadas estas circunstancias, los niveles de precios influenciarían el tipo de cambio y con ello las relaciones comerciales con EU como se muestra a continuación.

En la comparación de ambas economías, de una parte se destaca la estabilidad de precios de EU; en tanto que la economía mexicana experimentó fuertes presiones inflacionarias. La coincidencia de la apertura y la volatilidad cambiaria llevó a la cúspide inflacionaria en 1995. Y es a partir de 2001 que el comportamiento de los precios se alinea disminuyendo de manera importante la brecha previa (Gráfica 1). De otra parte, considerando la paridad del poder adquisitivo y observando que el nivel de precios en México durante todo el

\footnotetext{
${ }^{1}$ Las turbulencias monetarias de inicio de 2015 hasta marzo provocadas por la caída en el precio del petróleo llevaron el tipo de cambio a un nivel similar al de 2009 de más de 15 pesos por dólar, con lo cual se estimulan exportaciones pero al mismo tiempo encarecen las importaciones; y de prevalecer el segundo efecto ello pone en una encrucijada el modelo secundario exportador que se basa en la importación de bienes intermedios.

${ }^{2}$ El valor de la moneda está determinado centralmente por la productividad.

${ }^{3}$ En Diciembre de 1994 las reservas eran 29 mil millones de dólares, que se redujeron a 6 mil millones en Enero de 1995.
} 
periodo de análisis fue superior al de EU, se tuvo un abaratamiento de la moneda nacional.

\section{Gráfica I}

INPC México-Estados Unidos 1990-2012

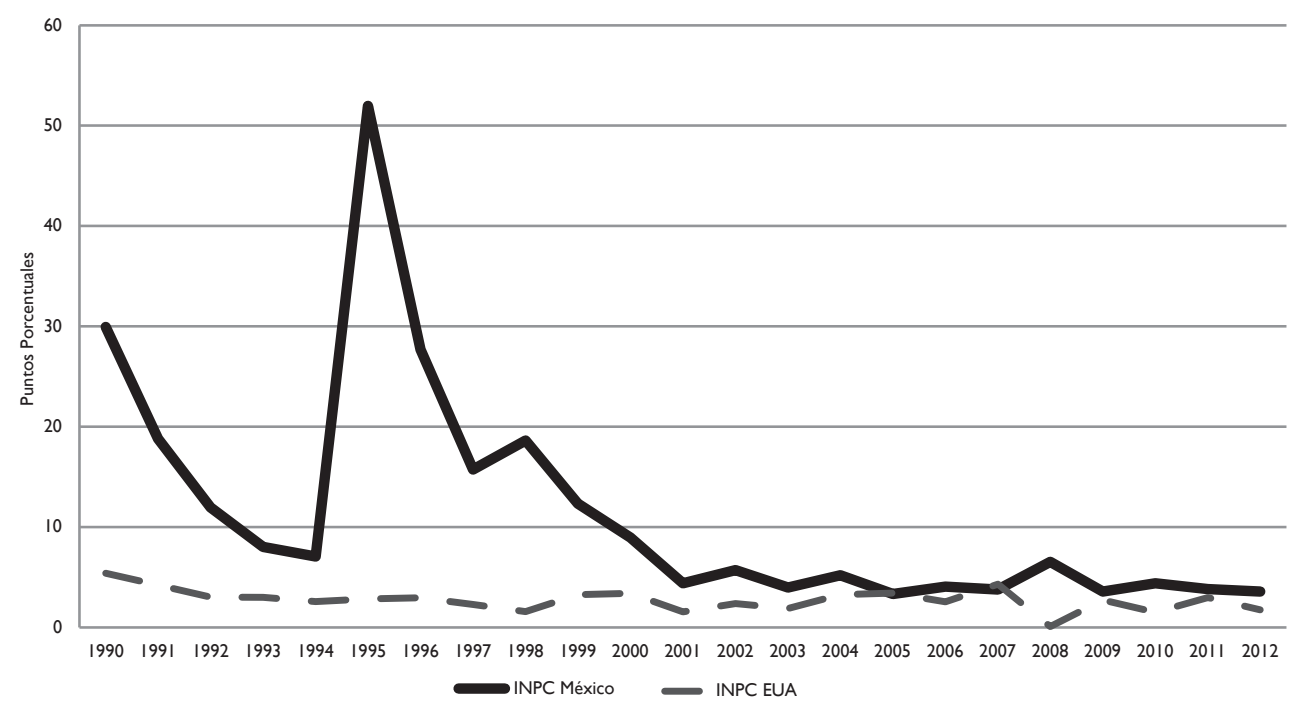

Elaboración propia con base en datos del Banco Mundial

De acuerdo a la depreciación del tipo de cambio en el periodo de estudio (1990-2013) se esperaría un aumento en las exportaciones debido a su abaratamiento y una posible reducción de las importaciones. Al respecto, de la Gráfica 2 se infieren dos resultados interesantes: el primero es que en la fase de alta turbulencia cambiaria (1995-1999), tanto exportaciones como importaciones tienen la misma tendencia y no hay una brecha significativa entre ambas; el segundo resultado es que la balanza parcial con EU siempre es positiva pero es con estabilidad y apreciación del tipo de cambio (2000-2008) que se abre la brecha de manera importante. Lo último contrasta con el hecho de que la balanza comercial total fue deficitaria, excepto tres años (1995-1997) que coinciden con la zona más álgida de la turbulencia cambiaria. ${ }^{4}$

\footnotetext{
${ }^{4}$ El déficit con China es lo que hace que en la suma de las relaciones comerciales totales la balanza sea negativa.
} 


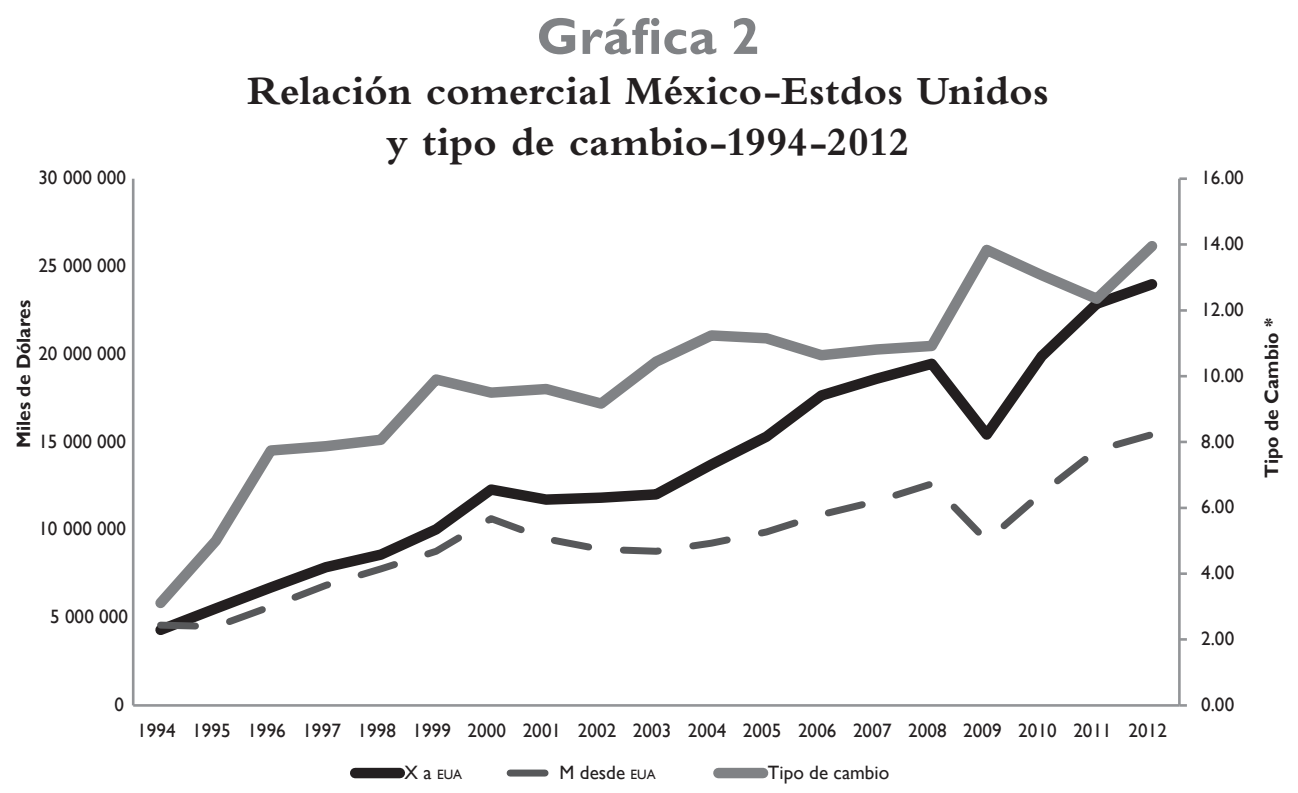

Elaboración Propia con base en datos de Banxico

El superávit comercial con EU va aunado a la concentración comercial con este país. ${ }^{5}$ Empero en este tenor debe señalarse que en el periodo 1994-2013 este indicador se redujo de 84 a 74\%; mas en el periodo de alta turbulencia cambiaria (1995-2000) la tasa de crecimiento anual de las exportaciones netas fue en promedio de $22 \%$, la cual en depreciación moderada se suavizó en $6.3 \%{ }^{6}$

En cuanto a las exportaciones manufactureras (Gráfica 3) se observa que el crecimiento no modificó su composición, únicamente incentivó el crecimiento de las industrias participantes. En efecto, si tomamos las tres ramas con mayor peso en las exportaciones manufactureras, que concentran $74 \%$ del total, se tiene que el sector más dinámico fue el de Productos metálicos, maquinaria y equipo.

\footnotetext{
${ }^{5}$ El 80\% de las exportaciones van hacia eu y éste provee 50\% de las importaciones.

${ }^{6}$ La fluctuación del tipo de cambio fue de 4\% anual en el periodo 2000-2008.
} 


\section{Gráfica 3}

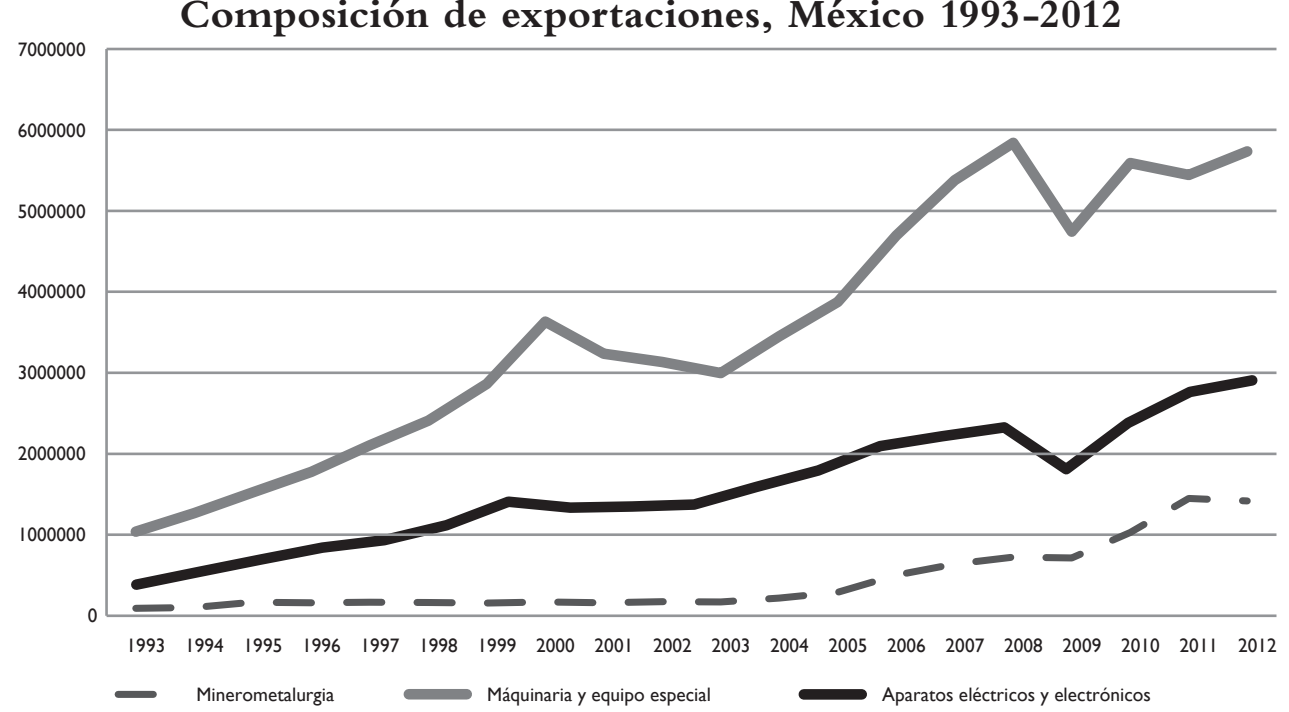

Elaboración propia con base en Banco de Información Económica (BIE) - INEGI

De igual forma, no se modificó la composición de las importaciones de las industrias con mayor peso en el total (74\%), sólo consolidó su crecimiento; siendo también el sector de Productos metálicos, maquinaria y equipo el de mayor dinamismo (Gráfica 4).

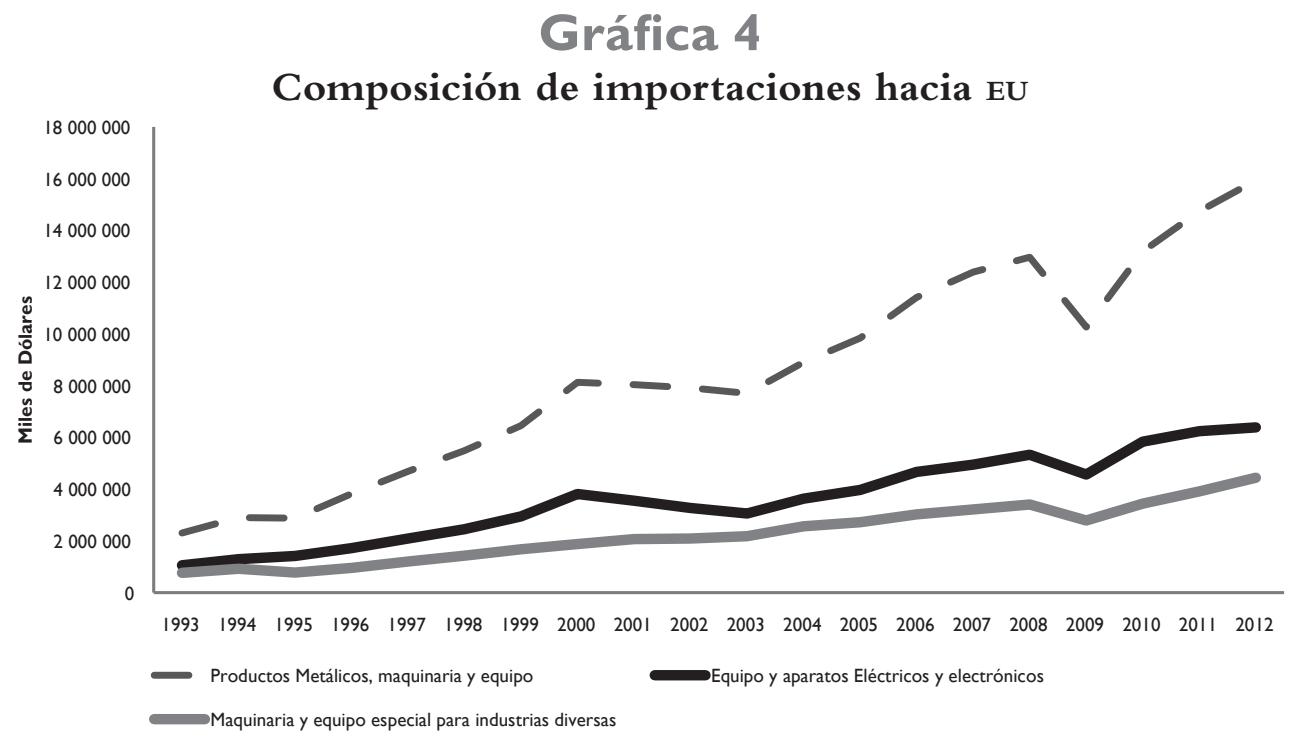

Elaboración propia con base en datos de BIE - INEGI 
Sin embargo, desde otro ángulo, al relacionar PIB, precios y exportaciones se tienen resultados mixtos. En efecto, en el periodo de estudio el año cismático fue 1995 con una devaluación de 55\%, inflación de 52\% y caída en el PIB de $-6.2 \%$; pero al mismo tiempo se dio un aumento en las exportaciones a Estados Unidos de 28\%. En cambio las recesiones posteriores de los años $2001 \mathrm{y}$ 2009 con PIB de -0.2 y $-6 \%$ en cada caso, no tuvieron un fuerte impacto en el tipo de cambio ni en el nivel de precios, siendo para estos años la variación negativa en las exportaciones de -4.6 y $-20.7 \%$, respectivamente; la última caída pudiera atribuirse a la recesión de EU en ese momento. Dadas estas cifras tan disímbolas, a continuación se hace una estimación del grado de influencia del producto de eU, así como del tipo de cambio en la balanza comercial considerando la evolución de estos indicadores de manera trimestral durante el periodo 1993-2012.

\section{El análisis empírico}

Se realizó una regresión lineal cuya variable dependiente corresponde al saldo de la balanza comercial entre EU y México (SBC), considerando como variables explicativas: el PIB Estadounidense (PIBEU), PIB Nacional (PIBMX) y Tipo de Cambio en su variación porcentual (TC). Para determinar que dichas series de tiempo sean estacionarias se realizó un test Dickey Fuller. Cuyos resultados mostraron la presencia de estacionariedad únicamente en la variable TC, por tanto el resto de las variables fueron utilizadas bajo la forma de primera diferencia siguiendo la estructura de regresión lineal:

$$
S B C_{t-1}=\beta+P I B E U_{t-1}+P I B M X_{t-1}+T C
$$

De lo anterior y una vez ejecutada la regresión se desprendieron problemas de correlación mismos que fueron corregidos con la utilización de un Autoregresor, por lo tanto la ecuación adquirió la siguiente forma:

$$
S B C_{t-1}=\beta+P I B E U_{t-1}+P I B M X_{t-1}+T C+A R(1)
$$

Obteniendo los siguientes resultados:

$$
S B C_{t-1}=-37.8-2.7 P I B E U_{t-1}+3 P I B M X_{t-1}+2.3 T C+[A R(1)=0.60]
$$


Para fines de nuestro análisis, de una parte se observa una influencia negativa del producto de EU en el saldo de la balanza comercial; y de otra parte, el producto nacional muestra una relación positiva con él mismo, de lo cual puede inferirse que la tendencia a la exportación de bienes y servicios hacia EU se debilita frente a un fortalecimiento de esta economía, considerando que en procesos de mayor producción eu tiende a aumentar su volumen de exportaciones hacia su socio comercial México; y respecto al tipo de cambio se muestra cómo la depreciación del mismo permite un mayor volumen de exportaciones. De lo anterior, y tomando en cuenta que el PIB cayó en mayor proporción en México que en EU, se infiere que la economía nacional presenta una influencia mayor hacia las importaciones desde eu en comparación con sus exportaciones, por tanto en periodos de recesión se reduce el superávit de la balanza comercial con EU.

Y al analizar sólo la relación entre exportaciones y tipo de cambio para el periodo 1996-2012, se tiene que la elasticidad de las exportaciones respecto al tipo de cambio es de 5.35, denotando la alta sensibilidad entre estas variables (Cuadro 1). Sin embargo hay diferencias muy marcadas de acuerdo a subperiodos seleccionados; así en 1996-2000 la sensibilidad de las exportaciones es la más alta y disminuye en las recesiones de 2001 y 2008 respectivamente.

\section{Cuadro I}

\begin{tabular}{|l|c|c|c|c|c|c|}
\hline \multicolumn{5}{|c|}{ México. Elasticidad Exportaciones-Tipo de cambio } \\
\hline & 1995 & $1996-2000$ & $2001-2008$ & 2009 & $2010-2012$ & $1996-2012$ \\
\hline $\begin{array}{l}\text { Elasticidad Exportaciones } \\
\text { /Tipo de cambio }\end{array}$ & 0.52 & 8.69 & 4.59 & 3.74 & 2.38 & 5.35 \\
\hline
\end{tabular}

Se concluye que la influencia de la producción de ambas naciones en la balanza comercial es mayor que la propiciada por el tipo de cambio, lo que permite conservar una relación estrecha entre importaciones y exportaciones aún en periodos de alta turbulencia cambiaria, mismos que coinciden con recesiones donde la elasticidad del tipo de cambio disminuye; pero de acuerdo a los resultados empíricos, lo anterior se debe a la magnitud de la producción de EU misma que es mayor a la nacional y presiona hacia una mayor importación de sus productos, relación misma que genera inestabilidad cambiaria. 


\section{Tasa de interés real y la Formación Bruta de Capital Fijo}

Si la apertura comercial y el TLC tienen un impacto positivo en la producción, ello debe reflejarse en la inversión, particularmente en aquella vinculada al sector externo. Usualmente la tasa de interés real y la inversión se relacionan de manera inversa, de tal forma que una baja consistente de la primera -ceteris paribus- debería estimular la segunda. Sin embargo se observa que a lo largo del periodo 1991-2012 la inversión, tomada como Formación Bruta de Capital Fijo (FBKF), es poco dinámica frente a la tasa de interés real (Gráfica 3), pudiendo concluir en este nivel de análisis que la variabilidad de la inversión en capital fijo no está relacionada de forma significativa con la tasa de interés real.

Gráfica 5

Variación porcentual PIB, FBKF y tasa de interés real, México 1991-2012

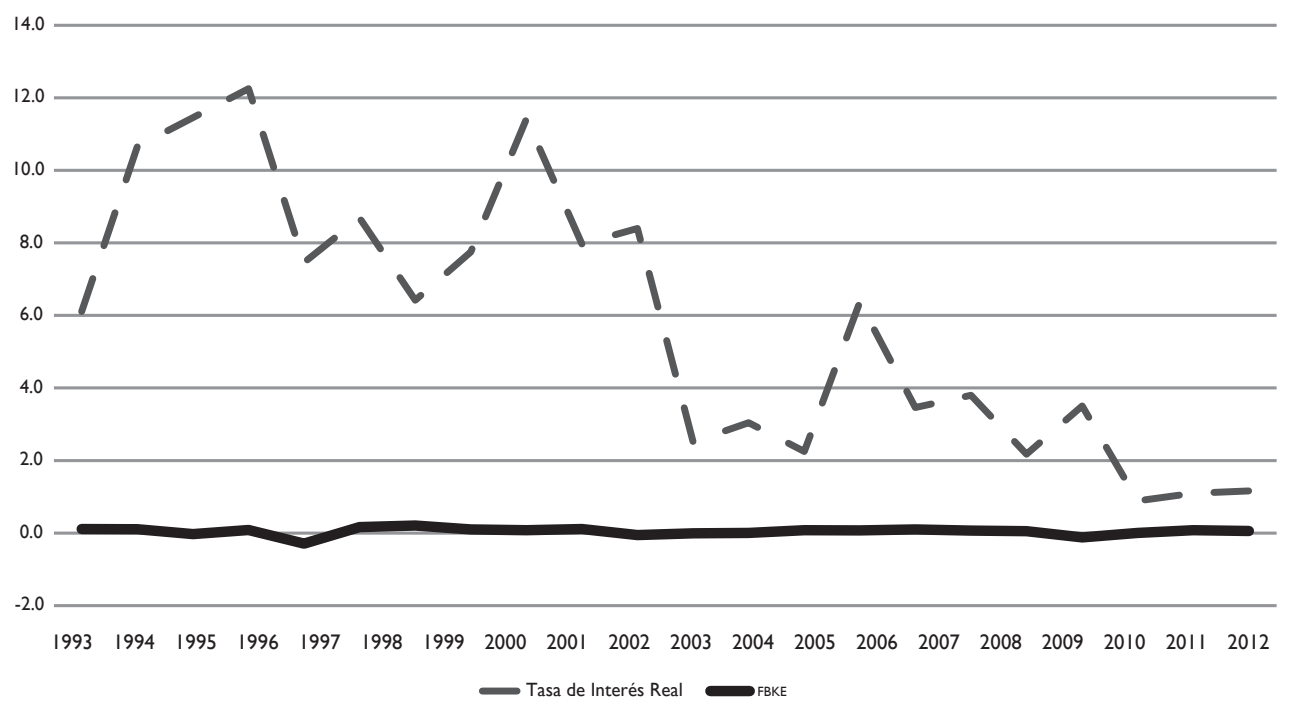

Elaboración propia con base en BIE-INEGI

El desempeño de la FBKF denota la falta de estímulo a la inversión directa en condiciones de economía abierta. Debido al comportamiento casi constante de FBKF se puede inferir que únicamente se ha pagado la depreciación de los bienes de capital habiendo una baja expansión de la planta productiva. Si bien las variaciones de la FBKF no presentan cambios significativos tras la apertura comercial, en cambio la composición de la misma acentúa una tendencia creciente hacia la importación de los bienes de capital (Gráfica 4), pues se 
presenta una brecha cada vez mayor con respecto al componente nacional a partir de 1996.

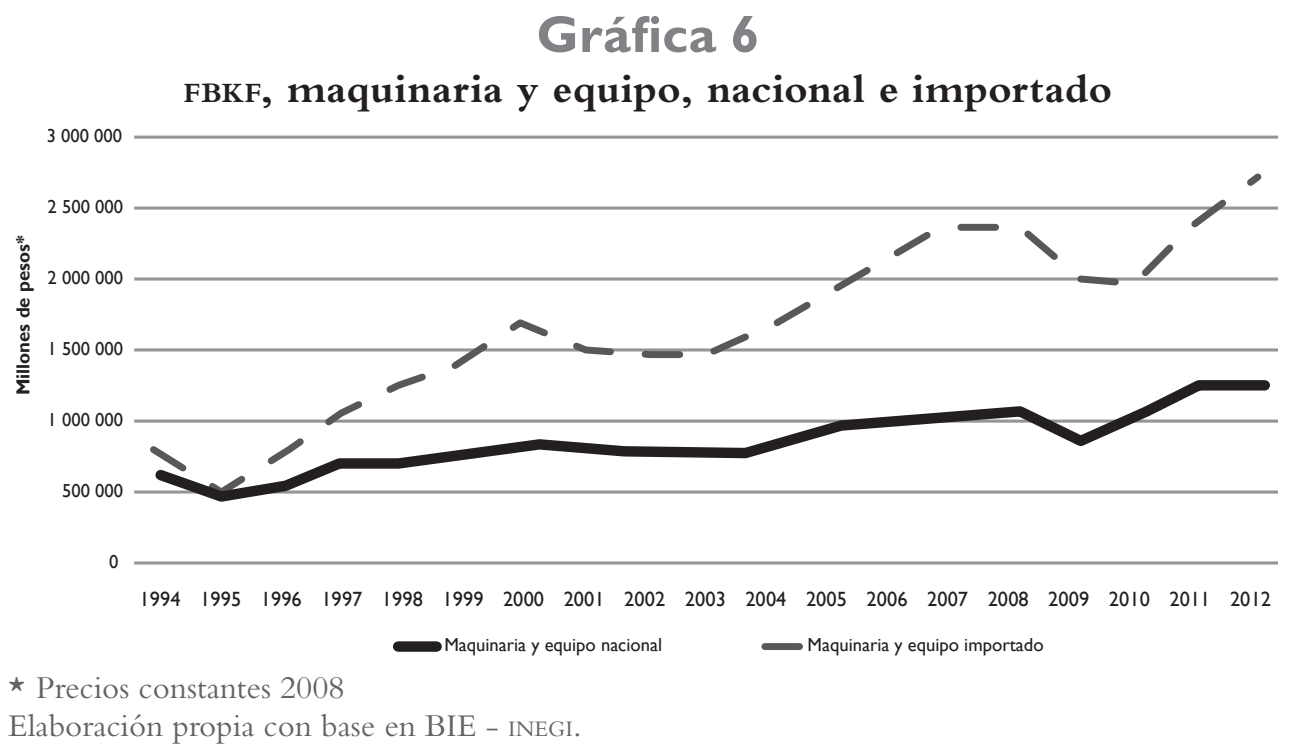

Dada la relación anterior, se buscó explicar si este comportamiento es particular a los componentes de inversión o bien a la economía en su conjunto. Así, considerando tanto la importación como exportación de bienes y servicios en relación al PIB, observamos que al final del periodo la brecha entre estos índices se redujo en relación al periodo previo a la firma del TLCAN (Gráfica 5). [Cabe señalar que si el impulso inicial (1994-1996) en el cual el índice X/ PIB superó al de M/PIB no se sostuvo, se explica por el efecto precio de corto plazo de la devaluación de casi $100 \% ;^{7}$ la brecha posterior implica que los problemas estructurales post apertura del sector externo no han sido resueltos o bien evolucionaron]. Si bien la devaluación del peso frente al dólar motivó el abaratamiento de las exportaciones, lo cual permitió el impulso inicial señalado; al concluir dicho sub periodo se estabilizó el déficit en balanza comercial, por lo cual se puede concluir que la dependencia de importaciones en México tan sólo se ha suavizado.

${ }^{7}$ El tipo de cambio pasó de tres a seis pesos por dólar de finales de 1994 a 1995. 


\section{Gráfica 7}

\section{Exportaciones e importaciones (\% $\%$ PIB) 1991-2012}

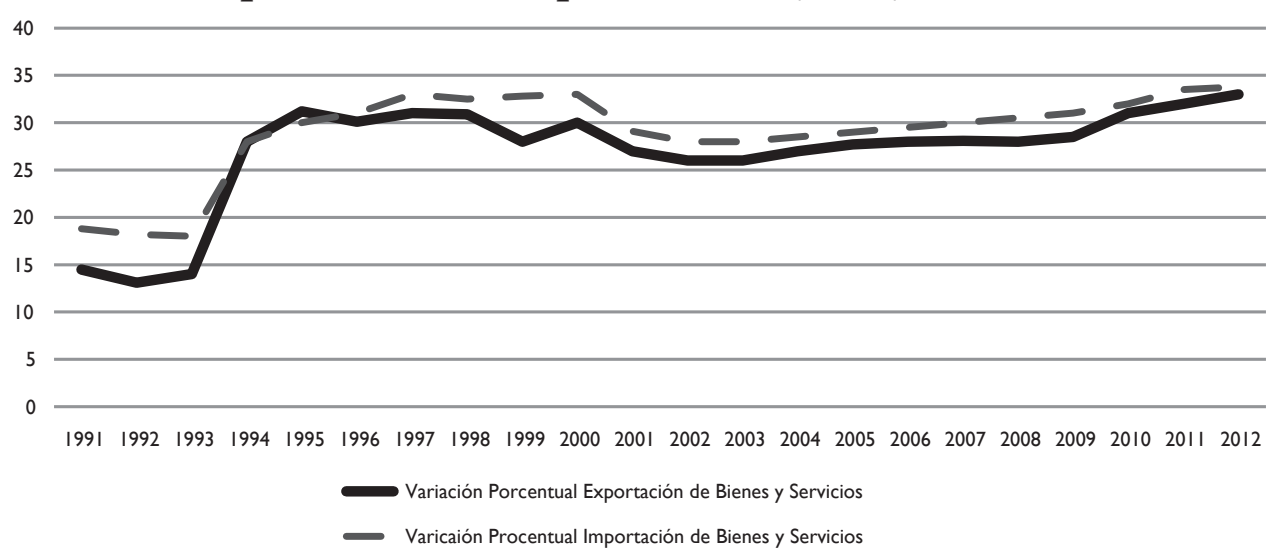

Elaboración propia con base en BIE-INEGI

El pobre desempeño de la inversión y la dependencia de la importación de capital fijo se dan pari passu con una aletargada evolución del producto nacional. ${ }^{8}$ Al respecto, Ros (2008) con antelación señala que ello se explica por la baja tasa de acumulación de capital físico. Cabe recordar que el énfasis en la economía de mercado plantea la mínima intervención del Estado. Y en el tema de inversión se asume que el posible hueco de la inversión pública lo cubriría la inversión privada (efecto sustitución); al respecto, la IED ha sido muy dinámica al pasar de 12 mil millones de dólares en 1991-1993 a 46 mil millones en 2003-2005, previo a la crisis; y situarse cerca de 50 mil millones en 20102012 (CNIE, 2013). En consecuencia, el bajo desempeño de la acumulación se explicaría más bien por la caída de la inversión pública (Cuadro 2).

\section{Cuadro 2}

\section{Inversión Fija Bruta/PIB}

\begin{tabular}{|l|c|c|}
\hline & 1980 & 2010 \\
\hline Total & 18.9 & 21.2 \\
\hline Privada & 11.8 & 16.4 \\
Pública & 7.1 & 4.8 \\
\hline
\end{tabular}

Fuente CEPAL

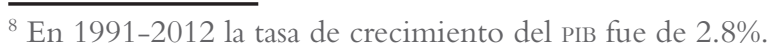


Puede agregarse la evidencia empírica encontrada por Caballero (2012) en el sentido de que "el aumento de un punto porcentual del gasto público se traduce en un incremento de la inversión privada, con un rezago de un periodo, de casi un punto porcentual (0.93\%)". Por lo tanto la inversión pública tiene un efecto positivo sobre la inversión privada, rechazando el efecto expulsión planteado por la teoría convencional.

A dichas circunstancias coadyuva el efecto negativo que existe en la inversión privada como consecuencia de un incremento en el tipo de cambio real, de tal manera que la apertura estimula el equilibrio comercial, así como la depreciación cambiaria al sector exportador; sin embargo se genera en detrimento de los niveles de inversión privada aunados al pobre desempeño de la inversión pública tras la reducción del déficit público, como respuesta a las necesidades del nuevo modelo.

Los bajos niveles de inversión no impulsan la productividad de manera consistente pues esto depende en gran medida de insumos importados, en su mayoría bienes intermedios que forman parte de un proceso de producción interno de bajo valor agregado; Brown y Domínguez (2013) muestran evidencia de que la variación promedio de este último para el periodo 1993-2009 fue de 1.80\%, con una tendencia cercana al estancamiento de la productividad total de los factores cuya variación fue de $1.07 \%$ después de la firma del TLCAN y de $1.00 \%$ posterior a la crisis de 2008, repercutiendo en una escasa capacidad de arrastre para la industria local.

En consonancia con lo anterior, de acuerdo con el Foro Económico Mundial (WEF, 2012) la economía mexicana ha perdido competitividad al pasar del sitio 33 en 1996 al 55 en el año 2013 en un grupo de 148 países.

En suma, siendo descendente la tasa de interés real se esperaría una tendencia ascendente de la FBKF, sin embargo la evidencia empírica demuestra lo contrario, denotando que las políticas pro-mercado han sido de bajo impacto en la inversión directa nacional, así como que la apertura no logró superar sino que acentuó la dependencia de componentes y bienes de capital importados para la producción.

\section{Finanzas públicas y déficit presupuestal.}

En buena medida, la política neoliberal se ha enfocado a la reducción del gasto público pues el alto déficit presupuestal que generaba se financiaba con deuda. Para enfrentar este problema se recurrió a la privatización de empresas icónicas como Aeroméxico, Mexicana de Aviación, Teléfonos de México y 
la reprivatización de la banca comercial; también se implementó una reforma fiscal que pretendía la reducción de subsidios, precios y tarifas del sector público y el aumento de la base fiscal.

La reducción del déficit fue exitosa; no obstante dicha estabilidad se vio diezmada tras la fuerte fuga de capitales por diversos acontecimientos políticos y militares que llevó a la crisis cambiaria de finales de 1994 y que culminó con la crisis de 1995 con una inflación de 50\%. El gasto público se incrementó como consecuencia del pago del servicio de deuda el cual fue compensado por el aumento en la tasa impositiva, conservando una tendencia al equilibrio presupuestal hasta los embates de la crisis del 2008 (Gráfica 7).

Gráfica 8

Ingreso y gasto público, \% del PIB

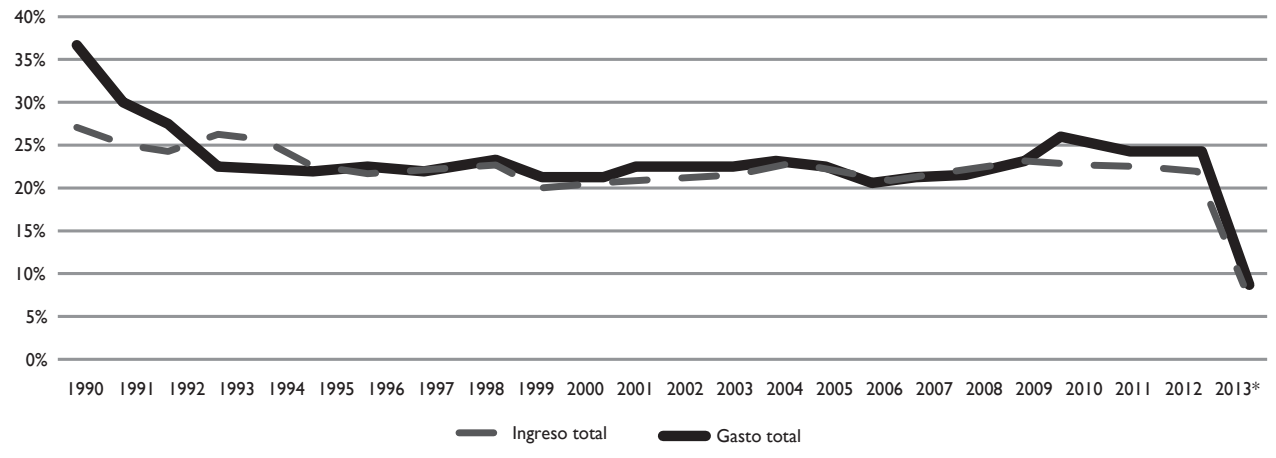

Elaboración propia con base en BIE - INEGI.

Las medidas antes mencionadas fueron eficientes para los efectos deseados; sin embargo, el aumento en la tasa impositiva, específicamente en el IVA durante el periodo 1995-2000, así como la reducción de gasto público, desincentivaron la inversión. Al analizar los ingresos tributarios se observa un incremento en los mismos a partir de 1996, presentando una tendencia ligeramente creciente en su conjunto (Cuadro 2).

\section{Cuadro 2}

Ingresos tributarios del gobierno federal en proporción del PIB

$\begin{array}{cccccc}1990-1992 & 1993 & 1996 & 1999 & 2004-2009 & 2010-2012 \\ 13.60 \% & 11.70 \% & 10.30 \% & 10.60 \% & 10.70 \% & 11.26 \%\end{array}$

Elaboración propia con base en BIE - INEGI. 
El aumento en el IVA e ISR si bien en la teoría convencional representan un obstáculo para la inversión en el corto plazo. Más de acuerdo a la evidencia empírica de Caballero (2012), para México un aumento de 1\% en el ISR reduce la inversión privada en $0.12 \%$, mientras que un aumento de $1 \%$ en el IVA lo hará en $0.24 \%$. Por lo tanto se observa que si bien una mayor recaudación por concepto de IVA e ISR desestimula la inversión privada, el efecto es mínimo en el caso del ISR; de donde se tiene que el incremento en gasto público de ésta recaudación por dichos conceptos, podría financiar el efecto negativo provocado por una mayor tributación, si estos ingresos son utilizados como gasto público de inversión, particularmente en infraestructura.

En la misma línea de razonamiento, se encuentra que el pago de intereses e inversión física pública como parte del ingreso total avalan que durante el periodo de aumento a las tasas impositivas el gasto público fue más intensivo en servicio de deuda, misma que duró hasta el año 2004, y es a partir del año 2009 que la relación se invierte siendo la inversión física la de mayor magnitud respecto al ingreso (Gráfico 9). No obstante se acentúa por una reducción en el pago de intereses y no por un impulso significativo en ésta última.

\section{Gráfico 9}

Gasto en pago de intereses e inversión física, 9\% del ingreso total

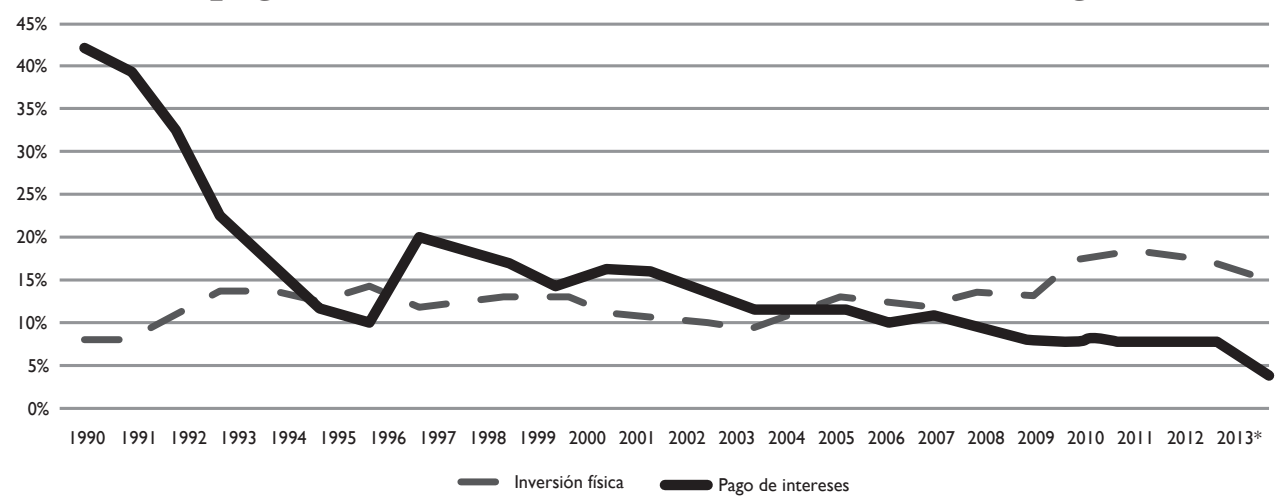

Elaboración propia con base en BIE - INEGI.

En este inciso se ha encontrado que el éxito en la reducción del déficit impacta de forma negativa a la inversión privada, esta relación surge no tanto por el aumento en tasas impositivas sino más bien por la contracción del gasto público en sectores productivos. En Moreno y Ros (2010) se tiene una evidencia similar en cuanto a que el determinante próximo de la caída en la tasa de inversión total es explicada por la caída en la tasa de inversión pública. De 
lo cual se desprende que un pobre desempeño de la acumulación va asociado con una balanza fiscal equilibrada.

\section{Conclusiones}

El análisis efectuado confirma que tras el proceso de apertura, se da una reestructuración lenta del aparato productivo, el cual se caracteriza por la existencia de un modelo dual de alto dinamismo en el sector exportador manufacturero el cual coexiste con el estancamiento del producto, evidenciando la ineficiencia de las políticas de apertura y de equilibrio fiscal, mismas que no convirtieron al comercio internacional en un motor de arrastre de la inversión interna.

De otra parte, el crecimiento de las exportaciones hacia EU tras la apertura es resultado de la fexibilización del tipo de cambio y tasas de interés variables, con una balanza comercial siempre positiva. El análisis empírico denota que en procesos recesivos la influencia del tipo de cambio disminuye acentuando una mayor influencia del PIB de eU en la balanza comercial en México; manteniendo una relación negativa la balanza comercial interna con respecto a EU y positiva con respecto al PIB nacional, relación misma que evidencia el alto grado de concentración conservado en la composisión del sector externo, lo que lleva a la especialización de manufacturas de bajo valor agregado que no modifican su estructura en contraste a la intensificación de su crecimiento.

En efecto las tasas de interés variables cuya tendencia es decreciente, no han incidido positivamente en la FBKF, acentuando una baja expansión productiva la cual depende de la importación de bienes de capital. La evidencia empírica señala que en el caso de México no existe un proceso de desplazamiento de la inversión privada por medio de la pública, por el contrario los bajos niveles de inversión privada se derivan de la contracción del gasto público.

Por lo tanto el gasto público en México es capaz de estimular la inversión privada, sí y solo sí éste es usado en sectores productivos. De acuerdo al análisis realizado, se da una expansión del ingreso público por concepto de tributación por medio del aumento en IVA e ISR, mismo que fue utilizado en el pago de servicio de deuda, dicha distribución de recursos aunado a políticas de equilibrio fiscal derivaron en un impacto negativo en la inversión privada. 
Economía Informa núm. 392 mayo - junio • 2015

\section{Bibliografía}

Brown, Flor y Domínguez Lilia (2013), "La productividad, reto de la industria mexicana”, En Comercio Exterior, Vol. 63, Núm. 3, Mayo y Junio, México.

Caballero Urdiales, Emilio y López Gallardo (2012), "Gasto público, impuesto sobre la renta e inversión privada en México”. En Investigación Económica, Vol. 71, Núm. 280 Abril/Junio, México.

Capdevielle, Mario (2005), “Globalización, especialización y heterogeneidad estructural en México". CEPAL.

Capdevielle, Mario (2007), "Heterogeneidad estructural, asimetrías tecnológicas y crecimiento en América Latina”. En Economía Informa, UNAM, Núm. 345, Marzo-Abril, México.

Cordera, Rolando (2015), La “Gran Transformación” del Milagro Mexicano. A 20 años del tLCAN: de la adopción a la adaptación, Problemas del Desarrollo, 180 (46).

CNIE (2013), Comisión Nacional de Inversión Extranjera. "Informe estadístico sobre el comportamiento de la inversión extranjera directa en México".

Fujii, Gerardo y Rosario Cervantes. (2013). "México: Valor agregado en las exportaciones manufactureras". En Revista CEPAL 109, Abril.

Góngora Pérez, Juan Pablo (2012), "La formación bruta de capital fijo en México". En Comercio Exterior, Vol. 62, Núm. 6, Noviembre-Diciembre. México.

Ibarra Puig, Vidal I. (2013), "Lecciones de la globalización: el caso de México, 1986-2008”. En Comercio Exterior, Vol. 63, Núm. 3, Mayo-Junio. México.

Kehoe, Timothy J. y Felipe Meza. (2013), “Crecimiento rápido seguido de estancamiento: México (1950-2010)". En Trimestre Económico, Abril/Junio.

Loría, Eduardo (2009), "Sobre el lento crecimiento económico de México. Una explicación estructural”. En Investigación Económica, Vol. 68, Núm. 270, Octubre/ Diciembre, México.

Morales, Josefina (2013), “La inversión extranjera directa en México 1980-2011, Samuel Lichtenstejn, Xalapa, Universidad Veracruzana, Biblioteca, 2012”. En Problemas del Desarrollo, Vol. 44, Núm. 174, Julio/Septiembre. México

Ros, Jaime (2008), "La desaceleración del crecimiento económico en México desde 1982” en El Trimestre Económico. Vol. 75. Núm. 299, Julio-Septiembre. México.

Ruiz, Clemente (2015), Reestructuración productiva e integración. TLCAN 20 años después, Problemas del Desarrollo, 180 (46).

Secretaría de Economía (2012), "Análisis de la Competitividad de México, Cierre 2011". México

WEF (2013), World Economic Forum, Davos Suiza. 